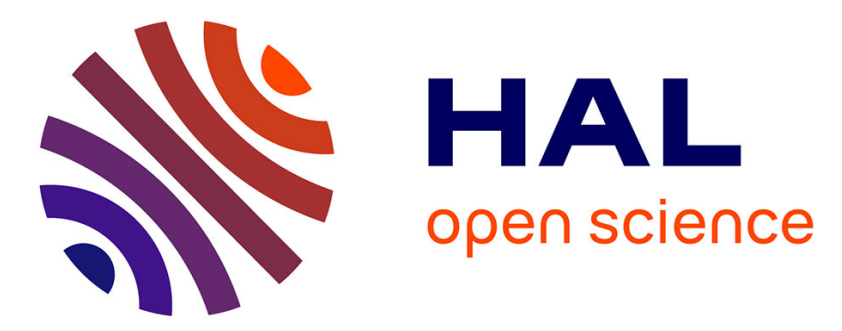

\title{
Visual contrast sensitivity in school-age Guadeloupean children exposed to chlordecone
}

\author{
Dave Saint-Amour, G. Muckle, A. Gagnon-Chauvin, F. Rouget, Christine \\ Monfort, L. Michineau, J.-P. Thomé, P. Kadhel, Luc Multigner, Sylvaine \\ Cordier
}

\section{To cite this version:}

Dave Saint-Amour, G. Muckle, A. Gagnon-Chauvin, F. Rouget, Christine Monfort, et al.. Visual contrast sensitivity in school-age Guadeloupean children exposed to chlordecone. NeuroToxicology, 2020, 78, pp.195-201. 10.1016/j.neuro.2020.02.012 • hal-02569808

\section{HAL Id: hal-02569808 \\ https://hal-univ-rennes1.archives-ouvertes.fr/hal-02569808}

Submitted on 14 May 2020

HAL is a multi-disciplinary open access archive for the deposit and dissemination of scientific research documents, whether they are published or not. The documents may come from teaching and research institutions in France or abroad, or from public or private research centers.
L'archive ouverte pluridisciplinaire HAL, est destinée au dépôt et à la diffusion de documents scientifiques de niveau recherche, publiés ou non, émanant des établissements d'enseignement et de recherche français ou étrangers, des laboratoires publics ou privés. 


\section{Visual contrast sensitivity in school-age Guadeloupean children exposed to chlordecone}

Dave Saint-Amour ${ }^{1,2,3}$ Gina Muckle $^{4,5}$, Avril Gagnon-Chauvin ${ }^{1,2}$, Florence Rouget ${ }^{6}$ Christine Monfort ${ }^{7}$, Leah Michineau ${ }^{7}$, Jean-Pierre Thomé ${ }^{8}$, Philippe Kadhel ${ }^{9}$, Luc Multigner ${ }^{7}$, Sylvaine Cordier ${ }^{7}$

${ }^{1}$ Department of Psychology, Université du Québec à Montréal, Montréal, Québec, Canada.

${ }^{2}$ Sainte-Justine University Hospital Research Center, Montréal, Québec, Canada.

${ }^{3}$ Department of Ophtalmology, Université de Montréal, Montréal, Québec, Canada.

${ }^{4}$ School of Psychology, Université Laval, Québec, Canada.

${ }^{5}$ Population Health and Optimal Health Practices Research Unit, CHU de Québec Research Centre, Québec, Canada;

${ }^{6}$ CHU de Rennes, Univ Rennes, Inserm, EHESP, Irset (Institut de recherche en santé, environnement et travail) - UMR_S 1085, Rennes, France.

${ }^{7}$ Univ Rennes, Inserm, EHESP, Irset (Institut de recherche en santé, environnement et travail) - UMR_S 1085, Rennes, France.

${ }^{8}$ EAE-CART (Laboratoire d'Ecologie Animale et d'Ecotoxicologie-Centre de Recherche Analytique et Technologique), Université de Liège, B-4000, Liège, Belgium

${ }^{9} \mathrm{CHU}$ de Pointe-à-Pitre, Univ Antilles, Univ Rennes, Inserm, EHESP, Irset (Institut de recherche en santé, environnement et travail) - UMR_S 1085, Pointe-à-Pitre, France;

Corresponding author: Dave Saint-Amour, Department of Psychology, Université du Québec à Montréal, C.P. 8888 Succ. Centre-Ville, Montréal, Canada. Phone: 514-9873000 x7698, email : saint-amour.dave@uqam.ca

\section{Highlights}

- Children at 7 years exposed to chlordecone in Guadeloupe were enrolled

- The association between pre- and postnatal chlordecone exposure and visual contrast sensitivity was examined

- Prenatal chlordecone exposure was associated with lower contrast sensitivity

- Postnatal chlordecone exposure was associated with lower contrast sensitivity but only in boys

\section{Abstract}


Recent evidence suggests that prenatal exposure to chlordecone, a persistent organochlorine pesticide that was used intensively in the French West Indies, affects infant neurodevelopment. The aim of the present study was to evaluate the association between prenatal and postnatal chlordecone exposures on visual contrast sensitivity in 285 children aged from 7.1 to 8 years old (mean age $=7.68 \pm 0.21$ years; sex ratio $=54 \%$ girls) in a Guadeloupean prospective birth cohort (TIMOUN). The Freiburg Visual Acuity and Contrast Test (FrAcT) was used to assess visual contrast sensitivity. Chlordecone concentrations were measured in blood samples at birth (cord blood) and in children at testing time to estimate pre- and postnatal exposure, respectively. Exposures were categorized into three groups and were also log-transformed and considered as continuous variables. Multiple linear regression models were performed on all children taking into account various potential confounders, including maternal characteristics (age, education, intellectual functioning, alcohol and tobacco use during pregnancy). Potential moderation effect of sex was also examined. Results showed that higher cord plasma chlordecone levels were associated with lower contrast sensitivity. Although child chlordecone levels was not associated with the FrAcT, sex-specific stratified analyses revealed significant associations in boys. Associations between postnatal exposure and FrACT scores in girls were null. This study indicates that exposure to chlordecone in utero and during childhood may impair visual contrast sensitivity at school age, particularly in boys.

\section{Introduction}


Organochlorine (OC) compounds are persistent organic pollutants that were massively used in agriculture and residential settings. Although mostly banned by the late 1970s, humans are still exposed to these industrially synthesized molecules because of their high stability and resistance to environmental degradation. The impact of OC exposure on human health has been studied in particular in the context of metabolic diseases (Lee et al., 2014), reproductive health (Vested et al., 2014) and child development (Vrijheid, Casas, Gascon, Valvi, \& Nieuwenhuijsen, 2016). Although there is strong evidence from longitudinal birth cohorts that prenatal exposure to OC pesticides is associated with impairments of motor and cognitive development (Eskenazi et al., 2006; Puertas et al., 2010; Ribas-Fito et al., 2003; Ribas-Fito et al., 2006; Sagiv et al., 2010; Torres-Sanchez et al., 2007), very few studies have investigated the impact on sensory functions (Cartier et al., 2014; Riva et al., 2004). Yet, it is very important to understand the neurological burden resulting from environmental contaminant exposure, especially since there are cases in the literature showing no adverse associations with cognitive functions but with alterations of sensory functions, and vice-versa. For instance, in a study that examined the consequences stemming from prenatal exposure to organophosphate insecticides, Cartier and colleagues found no association with altered cognitive function in 6-year-old children from the PELAGIE mother-child cohort in France (Cartier et al., 2016), but found significantly decreased visual contrast sensitivity function in those children (boys only) (Cartier et al., 2018).

Chlordecone, an OC pesticide, was extensively used until 1993 in the French West Indies to control banana root borers. This molecule is highly stable and resistant to 
environmental degradation and therefore contaminates soils, water sources and crops for several decades (Cabidoche et al., 2009; Coat et al., 2011). As a result, populations of the French West Indies, including pregnant women, are exposed to chlordecone through the consumption of contaminated food and of drinking water (Dubuisson et al., 2007). Since chlordecone is known to cross the placental barrier (Kavlock, Chernoff, Rogers, \& Whitehouse, 1980), in utero exposure from maternal intake might result in a window of higher susceptibility for the offspring, which can be harmful given the well-known sensitivity of the fetus to toxic disturbances (Grandjean \& Landrigan, 2006). In addition to prenatal exposure, postnatal exposure can occur via breastfeeding and diet. In fact, in the French West Indies, food-related exposure to chlordecone above the reference dose (i.e., the "no effect threshold" dose) is more common in 3-to-5-year-old children than in adults (Godard \& Guldner, 2011).

The toxicity of chlordecone was first recognized decades ago following an accidental excessive exposure in workers in a chlordecone-producing factory located in Hopewell, United States (Cannon et al., 1978; Taylor, Selhorst, Houff, \& Martinez, 1978). In addition to signs of toxicity on the skin, in the liver and in the endocrine system, neurological impairments were also observed, such as tremors, enhanced startle responses, staggering speech, memory loss, and visual disturbances. Visual symptoms were characterized by difficulties in maintaining stable fixation, including nystagmus, and blurred vision, but visual acuity remained within the normal range. Of note, some of the workers complained of neurological symptoms several years after cessation of exposure (Taylor, 1982). The mechanisms of action causing chlordecone neurotoxicity 
involves alterations in cell metabolism, namely in the enzymatic activity of the ATPases and calcium homeostasis (End, Carchman, \& Dewey, 1981; Komulainen \& Bondy, 1987), as well as in several neurotransmitter systems (Desaiah, 1985), altering various functions of the central nervous system. Furthermore, chlordecone possesses well-defined estrogenic activity in vivo and in vitro (Hammond, Katzenellenbogen, Krauthammer, \& McConnell, 1979; Kuiper et al., 1998; Lemaire, Mnif, Mauvais, Balaguer, \& Rahmani, 2006).

In the early 2000s, two epidemiological studies reported cognitive and motor impairments following chlordecone exposure in Guadeloupean infants from the prospective birth cohort TIMOUN (Boucher et al., 2013; Dallaire et al., 2012). The authors found an association between pre- and postnatal exposure to chlordecone and short-term memory at 7 months of age, as well as fine motor deficits at 18 months of age. These results are consistent with reports in Hopewell workers of memory and motor impairments. In the study of Dallaire et al. (2012), visual acuity, i.e., the ability to discern fine details, was also measured using the Teller Acuity Cards and no association was detected between infant visual acuity and chlordecone concentrations, for prenatal nor postnatal exposure. Of note, visual acuity was also found to be intact in the chlordecone (Kepone) poisoning workers, where blood levels were about 1000 times higher than those measured in Guadeloupe (Cannon et al., 1978). These results suggest a potential lack of sensitivity of acuity tests in detecting chlordecone-related effects on visual functions. 
The present study aimed to evaluate the impact of chlordecone exposure on visual functions in school-aged children from the TIMOUN birth cohort by assessing contrast sensitivity. In contrast to visual acuity, which measures the ability to recognize smaller and smaller stimuli at maximal contrast (e.g., a black letter on a white background), contrast sensitivity measures the ability to see a stimulus of decreasing contrast or light intensity. Contrast sensitivity measures have been found to detect subtle changes in postretinal processing, which may not be revealed by visual acuity assessments, as the latter is easily disrupted by refraction errors in the eye. Thus, contrast sensitivity testing is thought to provide a more comprehensive and sensitive measure of visual function (e.g., Fillion et al., 2013; Frenette, Mergler, \& Bowler, 1991; Till, Westall, Koren, Nulman, \& Rovet, 2005).

\section{Materiel and methods}

\subsection{Participants}

The TIMOUN birth cohort was initiated to evaluate the potential impact of prenatal exposure to chlordecone on child development. Between November 2004 and December 2007, 1068 pregnant women were recruited during their third-trimester prenatal visit at public hospitals and antenatal care dispensaries in Guadeloupe. Questionnaires were administered at inclusion to document social, demographic, occupational, and medical family characteristics, as well as lifestyle habits. The maternal characteristics known as potential confounders were used in the present study for statistical control (see section 2.4 below). On the day of delivery, information about dietary habits and alcohol 
consumption during pregnancy were collected and a cord blood sample was obtained to document prenatal exposure to chlordecone and other environmental contaminants.

At 7 years of age, 1033 liveborn singleton children were invited to participate in a neuropsychological follow-up study at the hospital, which included an evaluation of their visual functions and the collection of a blood sample. A maternal interview documented major events and behavior during childhood, and the maternal nonverbal intellectual functioning was assessed with the Raven's Progressive Matrices (Raven, Raven, \& Court, 1998). In total, 444 families could not be contacted or refused to participate. Of the 589 remaining children, all completed a visual function evaluation. Participants were only included in the study analysis if chlordecone concentrations at birth (cord blood) and at the testing time (child blood) were available ( $\mathrm{n}=293$ ). The exclusion criteria for the present analysis were the following: birth before 34 weeks of gestation (n=5), 5-minute Apgar score $<7(n=0)$, genetic or neurological disorders ( $n=2$; epilepsy, traumatic brain injury), and/or medication intake at testing time ( $\mathrm{n}=1$, Ritalin). After applying all exclusion criteria, the final sample amounted to 285 children. Additional children were excluded because of technical problems $(n=1)$, lack of collaboration $(n=3)$ or due to forgetting their glasses at testing time $(n=5)$. All subjects gave informed consent before participating in this study. The appropriate French ethics committees approved all study procedures, including the informed consent forms.

2.2. Measurements of chlordecone and other contaminants 
Blood samples at birth (cord blood) and at the 7-year visit, were collected in EDTA tubes to document prenatal and childhood exposure to chlordecone respectively, and to other environmental contaminants. Plasma samples were stored at $-30{ }^{\circ} \mathrm{C}$ in Polypropylene Nunc® tubes following centrifugation. Chlordecone, polychlorinated biphenyl congener 153 (PCB-153), dichlorodiphenyl dichloroethene (DDE) and lipids were measured in plasma. Total mercury $(\mathrm{Hg})$ and lead $(\mathrm{Pb})$ were quantified in whole blood. Determination of chlordecone and PCB-153 concentrations were done by the Center for Analytical and Research Technology at Liege University (Belgium). Contaminant concentrations were analyzed by high-resolution gas chromatography (Thermo Quest Trace 2000).

Preparation of samples and quantification method were previously described (Multigner et al., 2010). The limit of detection (LOD) was $0.06 \mu \mathrm{g} / \mathrm{L}$ for chlordecone in cord blood, 0.02 for child chlordecone, and $0.05 \mu \mathrm{g} / \mathrm{L}$ for PCB-153 and DDE. Total cholesterol and triglycerides in plasma were determined by standard enzymatic procedures (DiaSys Diagnostoc Systems GmbH; Holzheim, Germany) and total lipid concentrations were calculated as described by Bernert et al. (2007). Blood $\mathrm{Hg}$ and $\mathrm{Pb}$ concentrations were measured by inductively coupled plasma mass spectrometry (ICP-MS) at the laboratory of the "Centre de toxicologie du Québec". For Hg determination, blood samples were diluted 20 -fold in a solution containing ammonium hydroxide before analysis. The LOD for $\mathrm{Hg}$ and $\mathrm{Pb}$ were $0.4 \mu \mathrm{g} / \mathrm{L}$ and $2 \mu \mathrm{g} / \mathrm{L}$ respectively, and each run of samples included a standard.

\subsection{Functional Acuity Contrast Test (FrACT)}


Participants were seated at a distance of 2 meters from the computer screen (1024 x 768 pixels). The assessment was conducted by a trained nurse, blind to the participant chlordecone exposure. Participants with prescription glasses were asked to wear them for the duration of the task. Visual acuity and contrast threshold were assessed using the FrACT. The FrACT is an 8-minutes computerized visual screening battery developed by Michael Bach (Bach, 1996), which has been validated in different populations and for different age groups, including preschool children (Dennis et al., 2004; Lai, Wang, \& Hsu, 2011; Loumann Knudsen, 2003; Molloy et al., 2016; Schulze-Bonsel, Feltgen, Burau, Hansen, \& Bach, 2006; Van den Boomen, de Graaff, de Jong, Kalkman, \& Kemner, 2013). Auditory feedback was given on a trial-by-trial basis (high-frequency tones after correct responses, and low-frequency tones after incorrect responses) to enhance each participant's comfort (Bach \& Schafer, 2016). A short practice run (about 5 trials) was administrated before testing to make sure that the task was well understood. First, the visual acuity test, which consists of a ring with a gap ("C" " shape optotype), was administrated (Figure 1a). The testing duration was approximately 4 minutes. The optotype was presented randomly among four different positions for each trial. Participants were instructed to indicate the location of the gap by pressing on a 4-arrow keypad, i.e., up, down, right or left. Perceptual thresholds were obtained from an adaptive staircase procedure implemented into the program (Best-PEST algorithm). The size of the optotype was automatically adjusted across trials according to the participant's performance (e.g., if the participant answered correctly, the stimulus size was reduced on the next trial). The acuity of each participant was calculated as a Snellen fraction score, so that higher scores indicated better performance. Second, contrast thresholds were 
tested, i.e., the lowest contrast level at which the the location of the gap was correctly detected (Figure 1b). The testing duration was approximately 4 minutes. Contrast of the optotype (with a constant and large size, i.e. 50 arc minutes width of visual angle) changed automatically across trials according to the participant's performance. Scores were then converted in contrast sensitivity (1/threshold), so that higher scores indicated better performance.
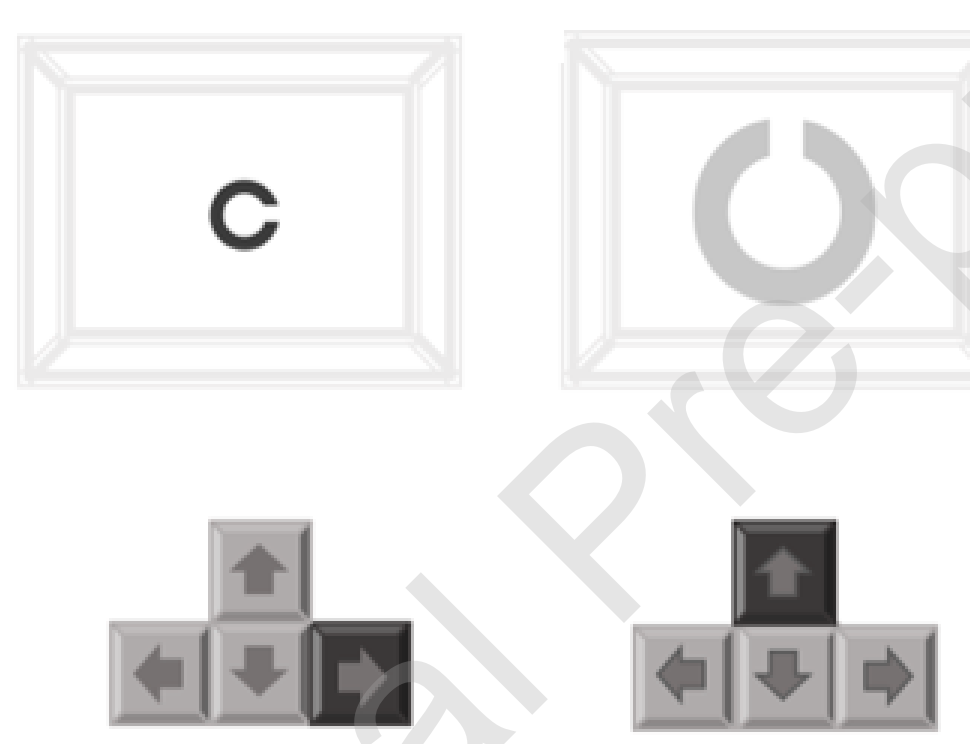

Figure 1. Visual acuity (left) and contrast sensitivity (right) measured using the FrACT. For visual acuity, participants selected the arrow corresponding to the perceived orientation of Landolt-C varying in size (illustrated here by the right gap). For contrast sensitivity, participants selected the arrow corresponding to the perceived orientation of Landolt-C varying in contrast (illustrated here with an up gap).

\subsection{Potential covariates}

The following variables were considered as potential confounders: age (in years), child sex, child birth weight (in grams), breastfeeding (none, <3 months, 3-7 months, >7-18 months or >18 months), age of the mother at the time of birth (in years), maternal educational level (12 $2^{\text {th }}$ grade (bac) or higher), tobacco smoking (yes/no), alcohol 
drinking during pregnancy (at least one drink during the preceding week or one "binge drinking" session in the past three months reported on either one of the two questionnaires administered at enrolment and after delivery), and the Raven's Progressive Matrices maternal score. Prenatal and/or childhood exposure to other contaminants as assessed by cord and child blood concentrations of PCB-153, DDE, $\mathrm{Hg}$ and $\mathrm{Pb}$ were also examined.

\subsection{Statistical analysis}

Cord and child chlordecone concentrations were categorized into three groups ( $<$ LOD, $\geq$ LOD - median, >median) and were also log-transformed and considered as continuous variables. All other exposure variables (PCB-153, DDE, $\mathrm{Pb}$, and $\mathrm{Hg}$ blood concentrations) were log-transformed. When chlordecone and other contaminant concentrations were analyzed as continuous variables, we imputed values of blood concentrations below the LOD using the likelihood method (Jin, Hein, Deddens, \& Hines, 2011), under the assumption that contaminant concentration is log-normally distributed. Children's contrast sensitivity scores were also log-transformed.

Multiple linear regressions were used to assess the associations between prenatal and childhood exposure to chlordecone and children's FrACT scores. Age and sex of the child, as well as total blood lipid concentrations were systematically included in the models. Other covariates were included in the models if they were associated with both chlordecone exposure and FrACT scores at $\mathrm{p} \leq 0.2$ or if they were highly associated ( $\mathrm{p} \leq$ 0.05) with FrACT scores alone. Models explored associations with prenatal exposure or 
child exposure separately and with mutual adjustment. Since chlordecone is a compound with recognized hormonal activity and since previous sex-specific associations have been reported between chlordecone exposure and child growth (Costet et al., 2015), or neurodevelopment (Boucher et al., 2013), we examined the interaction term of sex by chlordecone exposure (continuous variable) in the regression models. A liberal statistical criterion $(\mathrm{p}<0.2)$ of the interaction term was used to justify follow-up sex-specific stratified analysis.

\section{Results}

Descriptive characteristics of the participants are presented in Table 1. The proportion of girls in the sample was slightly higher than boys ( $54.4 \%$ and $45.6 \%$, respectively). Children who needed wearing glasses (29.8\%) were as many girls (30.3\%) as boys (29.2\%). Mothers' ages at the time of delivery ranged from 15.1 to 45.1 years old, and half of them (49.5\%) had an education level of $12^{\text {th }}$ grade (bac) or higher. Alcohol drinking (yes/no) documented twice during pregnancy was reported by $2.5 \%$ of the women (at enrolment and after delivery), and only $2.8 \%$ reported smoking at the beginning of pregnancy. The average gestation age was 38.5 weeks (Median $=39$ weeks) with a range of 34 to 41 weeks. Finally, the majority of participating children (85.3\%) were breastfed. Median chlordecone concentrations among detected values were $0.3 \mu \mathrm{g} / \mathrm{L}$ in cord plasma and $0.08 \mu \mathrm{g} / \mathrm{L}$ in child blood samples. Prenatal and postnatal exposures were found to be poorly correlated $(r=0.139, p=.021)$. As for the FrACT visual assessments scores, the vast majority of children (91\%) had visual acuity within the 
normal range, i.e., a Snellen fraction ratio of at least 0.8 (i.e., 20/25 or better), with a median of 1.33 . The average contrast sensitivity score was $4.5 \%($ median $=3.15 \%)$, ranging between $0.14 \%$ and $16.67 \%$.

The associations between chlordecone exposure variables and contrast sensitivity scores are illustrated in Table 2. Results show that higher cord plasma chlordecone levels were associated with lower FrACT scores in the continuous adjusted model $(\beta=-0.068,95 \%$ $\mathrm{CI}=-0.133,-0.002)$. A similar, although marginal, association was obtained after the additional statistical adjustment for the 7 -year-old child exposure $(\beta=-0.062,95 \% \mathrm{CI}=-$ $0.128,0.003)$. The interaction term between sex and chlordecone exposure was null, either in the adjusted models 1 or 2.

No associations were observed between chlordecone child concentrations and contrast sensitivity scores (Table 2), although higher child plasma chlordecone levels were marginally $(p<0.1)$ associated with lower FrACT scores in the continuous adjusted model $(\beta=-0.059,95 \% \mathrm{CI}=-0.128,0.010)$. This association vanished after additional adjustment for cord chlordecone concentrations $(p>0.1)$. Because the interaction terms between sex and chlordecone exposure were at $p<0.2$ (see details in Method section), follow-up sex-stratified analyses were conducted. As such, the same continuous adjusted 
models were applied in girls $(n=135)$ and boys $(n=115)$, separately. A significant negative association was observed exclusively in boys $(\beta=-0.112,95 \% \mathrm{CI}=-0.205$, $0.018, p=0.020$ versus $\beta=-0.015,95 \% \mathrm{CI}=-0.118,0.088, p=0.773$ in girls $)$. The association observed in boys remained significant after controlling for prenatal exposure $(\beta=-0.094,95 \% \mathrm{CI}=-0.188,0.000, p=0.049)$. Of note, FrACT scores and chlordecone concentrations, pre- and postnatal, did not significantly differ between boys and girls.

A sensitivity analysis was conducted by re-running the continuous adjusted regression models 2 (see Table 2) where exposure to other toxicants (see details in Method section) were found to be correlated with the outcome at $p<0.2$, that is child plasma PCB 153 concentrations and child blood $\mathrm{Pb}$. Results using the whole sample were in line with the principal analyses: Cord chlordecone concentrations and contrast sensitivity remained marginally associated $(\beta=-0.054,95 \% \mathrm{CI}=-0.118,0.010, p=0.100)$, and child chlordecone concentrations remained not associated with contrast sensitivity $(\beta=-0.043$, $95 \% \mathrm{CI}=-0.112,0.026, p=0.218)$. Regarding the additional sex-stratified analyses for child exposure, the significant association initially found in boys $(\beta=-0.094,95 \% \mathrm{CI}=-$ $0.188,0.000, p=0.049)$ was still present $(\beta=-0.101,95 \% \mathrm{CI}=-0.195,-0.007, p=$ $0.035)$.

\section{Discussion}


The present study aimed to evaluate the association between pre- and postnatal chlordecone exposures on visual contrast sensitivity in school-aged children. Results from continuous adjusted models showed that higher cord plasma chlordecone concentrations were significantly associated with lower contrast sensitivity. Although no association was found with child chlordecone concentrations, further sex-specific stratified analyses revealed a significant decrease in the contrast sensitivity scores of boys, but this reduction was not observed in girls. Interestingly, these findings resisted to the additional statistical adjustment for mutual chlordecone exposure (see Models 2, Table 2). The sensitivity analysis revealed that further adjustments for PCB-153 and $\mathrm{Pb}$ co-exposures did not change the results.

A decrease of contrast sensitivity can be due to alterations of ocular and/or retinal/brain processing (Waksman \& Brody, 2007). The contribution of ocular refraction errors can be reasonably excluded here. First, all of the tested children were wearing their glasses during the visual evaluation, despite the prescription for some of them not being up to date. Nonetheless, visual acuity was verified and found to be in the normal range for the vast majority (> 90\%) of the children. Furthermore, the stimulus size used for contrast sensitivity testing was quite large (low to medium spatial frequencies), which prevents alterations of stimulus visibility caused by potential refractive errors. In fact, deficits in contrast sensitivity observed at low spatial frequencies reflect predominantly defects in post-retinal neural processing (Waksman \& Brody, 2007). It is thus likely that the observed decrease in contrast sensitivity is mainly due to altered retinal and/or brain processing. 
Contrast sensitivity function relies on neural processing along the visual pathway, which involves various synaptic junctions and neurotransmitters. For instance, impaired contrast sensitivity has been found in pharmacological studies using drugs that alter GABAergic transmission, while visual acuity remained relatively intact (Blin et al., 1993; Haris and Phillipson, 1995; Giersch et al., 2006). Dopamine is another important neuromodulator of visual processing at both retinal and cortical levels (Albrecht, Quaschling, Zippel, \& Davidowa, 1996; Parkinson, 1989; Witkovsky \& Schutte, 1991). An improvement in contrast sensitivity has been demonstrated following administration of dopaminergic agonists in humans (Bulens, Meerwaldt, Van der Wildt, \& Van Deursen, 1987; Domenici, Trimarchi, Piccolino, Fiorentini, \& Maffei, 1985). Considering that organochlorine pesticides have also been proven to induce oxidative stress, mitochondrial dysfunction and caspase activation in dopaminergic neurons (Schuh, Richardson, Gupta, Flaws, \& Fiskum, 2009; Sharma, Zhang, Barber, \& Liu, 2010), and, on the other hand, that chlordecone can alter catecholamine activity - including dopamine - by decreasing their synaptic binding and uptake (Desaiah, 1985), one can reasonably hypothesize that associations between chlordecone exposure and contrast sensitivity dysfunction observed in the current study may potentially be mediated, at least partially, through dopaminergicrelated mechanisms.

Our results highlight the importance of assessing the functional integrity of sensory processing when evaluating chemical neurodevelopmental toxicity. The relevance of sensory assessment is supported by our previous studies in the French mother-child 
PELAGIE cohort, showing subtle functional visual processing alterations that were not detectable with cognitive evaluations (e.g., Cartier et al., 2018). Moreover, visual assessments in epidemiological cohort studies together with neuropsychological testing can aid in detecting participants needing adjustments due to potential visual deficits. This visual adjustment may, in turn, provide a better prediction of cognitive dysfunction in association with exposure, as demonstrated in the Faroese children in relation to mercury exposure (Grandjean et al., 2001).

The pattern of sex-dependent results found in the current study is noteworthy. In the study of Cartier et al. (2018), the authors reported a decrease of contrast sensitivity scores in 6-year-old children in association with prenatal exposure to organophosphate pesticides in boys, but not in girls. To our knowledge, this is the only study which has investigated the impact of pesticide exposure during pregnancy on child visual function. Other sex-dependent associations of neurodevelopmental deficits with pesticides in children have also been reported (e.g., Philippat et al., 2018; Rauh et al., 2015; Suarez-Lopez, Himes, Jacobs, Alexander, \& Gunnar, 2013; van Wendel de Joode et al., 2016; Wagner-Schuman et al., 2015). For instance, prenatal exposure to organophosphate pesticides was significantly associated with attention problems, with a stronger association found in the boys of a rural California longitudinal cohort (Marks et al., 2010). In another birth cohort study, prenatal exposure to organophosphate pesticides decreased working memory performance in boys, as assessed by the Wechsler Intelligence Scale for Children (WISC-IV), with no apparent deficits in girls (Horton, Kahn, Perera, Barr, \& Rauh, 2012), although the interaction term between exposure and 
child sex was not significant. It is important to note that the sex-specific results from all these studies need to be interpret with caution because of small sample size, differences in measured outcomes, participant characteristics or statistically power.

Although the underlying mechanisms are still unknown, genetic and hormonal factors are generally thought to play an important role in sex-related differences observed in epidemiological studies. A growing body of experimental evidence show multiple levels of sexual dimorphisms in the brain, i.e., sex differences in neurochemical phenotype, synapses, cell genesis, inflammatory mediators, epigenetics, and brain volume (McCarthy, Nugent, \& Lenz, 2017), which form a myriad of targets for neurotoxicants across sexes, providing biological plausibility for sex-specific mechanisms of action. In vivo rodent studies have shown that males are significantly more sensitive to organophosphate pesticides than females (Comfort \& Re, 2017). For instance, the cellular expression of inflammatory molecules and reactive oxygen species (ROS) has been found to be higher in males compared to female rats following dimethoate exposure (Astiz, Acaz-Fonseca, \& Garcia-Segura, 2014). Regarding chlordecone, sex-dependent effects of perinatal exposure have frequently been reported in animal studies, particularly in the development of behavioral and/or neural function (Cooper, Vodicnik, \& Gordon, 1985; Mactutus \& Tilson, 1985). These effects have been linked to the well-known property of chlordecone to alter pituitary hormones and estrogenic activity (Hammond et al., 1979; Hong, Hudson, Yoshikawa, Ali, \& Mason, 1985; Hudson et al., 1984; Kuiper et al., 1998; Lemaire et al., 2006). 
While the longitudinal design of the TIMOUN study and the computer-based assessment of visual contrast sensitivity are the primary strengths of our study, it also has limitations. First, we conducted a large number of analyses with multiple comparisons, which increases the likelihood of spurious associations. Nevertheless, our interpretations focused on the pattern of the results instead of on isolated findings. Second, the FrACT task was based on a single stimulus size, i.e., a large Landolt $\mathrm{C}$ optotype, which is composed of a mixture of low to medium spatial frequencies. It is common when measuring contrast sensitivity to use several and specific sine-wave spatial frequencies to estimate visual functions as a whole. For instance, Lebel et al. (1998) have reported specific deficits in the contrast sensitivity of Amazonian adults exposed to mercury, which were specific to high spatial frequencies, i.e., not detectable at low and medium ones.

\section{Conclusion}

Our study showed adverse associations between chlordecone exposures and children's contrast sensitivity scores, pointing to the importance of using visual assessments in cohort studies to better understand the impact of environmental contaminants on the brain integrity of children. The impact of postnatal exposure to chlordecone appeared moderated by child sex, such that the visual performance was decreased as a function of exposure, particularly in boys. Further epidemiological studies are necessary to replicate these findings, as well as laboratory studies to make reasonable causal inferences 
between chlordecone exposure and the development of brain processing, including sensory functions.

\section{Competing financial interests declaration}

No conflict of interest.

\section{Funding sources}

This work was supported by grants from the National Institute of Health and Medical

Research (INSERM ATC2003-A0313665), the National Research Agency (ANR

PNRA2006 2.24), the French Agency for Environmental and Occupational Health Safety

(AFSSET APR2003 RD-2004-010), the French Ministry of Environment (PNRPE

APR2005 CV05000142), and the General Health Directorate (DGS RMC11129NNA \& R17142NN).

\section{Declaration of interests}

The authors declare that they have no known competing financial interests or personal relationships that could have appeared to influence the work reported in this paper. 


\section{References}

Albrecht, D., Quaschling, U., Zippel, U., \& Davidowa, H. (1996). Effects of dopamine on neurons of the lateral geniculate nucleus: an iontophoretic study. Synapse, 23(2), 70-78. doi:10.1002/(SICI)1098-2396(199606)23:2<70::AID-SYN2>3.0.CO;2-D

Astiz, M., Acaz-Fonseca, E., \& Garcia-Segura, L. M. (2014). Sex differences and effects of estrogenic compounds on the expression of inflammatory molecules by astrocytes exposed to the insecticide dimethoate. Neurotox Res, 25(3), 271-285. doi:10.1007/s12640-013-9417-0

Bach, M. (1996). The Freiburg Visual Acuity test--automatic measurement of visual acuity. Optom Vis Sci, 73(1), 49-53. Retrieved from https://www.ncbi.nlm.nih.gov/pubmed/8867682

Bach, M., \& Schafer, K. (2016). Visual Acuity Testing: Feedback Affects Neither Outcome nor Reproducibility, but Leaves Participants Happier. PLoS One, 11(1), e0147803. doi:10.1371/journal.pone.0147803

Boucher, O., Simard, M. N., Muckle, G., Rouget, F., Kadhel, P., Bataille, H., . . Cordier, S. (2013). Exposure to an organochlorine pesticide (chlordecone) and development of 18-month-old infants. Neurotoxicology, 35, 162-168. doi:10.1016/j.neuro.2013.01.007

Bulens, C., Meerwaldt, J. D., Van der Wildt, G. J., \& Van Deursen, J. B. (1987). Effect of levodopa treatment on contrast sensitivity in Parkinson's disease. Ann Neurol, 22(3), 365-369. doi:10.1002/ana.410220313

Cabidoche, Y. M., Achard, R., Cattan, P., Clermont-Dauphin, C., Massat, F., \& Sansoulet, J. (2009). Long-term pollution by chlordecone of tropical volcanic soils in the French West Indies: a simple leaching model accounts for current residue. Environ Pollut, 157(5), 1697-1705. doi:10.1016/j.envpol.2008.12.015

Cannon, S. B., Veazey, J. M., Jr., Jackson, R. S., Burse, V. W., Hayes, C., Straub, W. E., ... Liddle, J. A. (1978). Epidemic kepone poisoning in chemical workers. Am J Epidemiol, 107(6), 529-537. Retrieved from https://www.ncbi.nlm.nih.gov/pubmed/78669

Cartier, C., Muckle, G., Jacobson, S. W., Jacobson, J. L., Dewailly, E., Ayotte, P., . . Saint-Amour, D. (2014). Prenatal and 5-year p,p'-DDE exposures are associated with altered sensory processing in school-aged children in Nunavik: a visual 
evoked potential study. Neurotoxicology, 44, 8-16.

doi:10.1016/j.neuro.2014.04.009

Cartier, C., Warembourg, C., Le Maner-Idrissi, G., Lacroix, A., Rouget, F., Monfort, C., . .. Chevrier, C. (2016). Organophosphate Insecticide Metabolites in Prenatal and Childhood Urine Samples and Intelligence Scores at 6 Years of Age: Results from the Mother-Child PELAGIE Cohort (France). Environ Health Perspect, 124(5), 674-680. doi:10.1289/ehp.1409472

Cartier, C., Warembourg, C., Monfort, C., Rouget, F., Limon, G., Durand, G., .. . Chevrier, C. (2018). Children's contrast sensitivity function in relation to organophosphate insecticide prenatal exposure in the mother-child PELAGIE cohort. Neurotoxicology, 67, 161-168. doi:10.1016/j.neuro.2018.05.004

Coat, S., Monti, D., Legendre, P., Bouchon, C., Massat, F., \& Lepoint, G. (2011). Organochlorine pollution in tropical rivers (Guadeloupe): role of ecological factors in food web bioaccumulation. Environ Pollut, 159(6), 1692-1701. doi:10.1016/j.envpol.2011.02.036

Comfort, N., \& Re, D. B. (2017). Sex-Specific Neurotoxic Effects of Organophosphate Pesticides Across the Life Course. Curr Environ Health Rep, 4(4), 392-404. doi:10.1007/s40572-017-0171-y

Cooper, J. R., Vodicnik, M. J., \& Gordon, J. H. (1985). Effects of perinatal Kepone exposure on sexual differentiation of the rat brain. Neurotoxicology, 6(1), 183190. Retrieved from https://www.ncbi.nlm.nih.gov/pubmed/2581194

Costet, N., Pele, F., Comets, E., Rouget, F., Monfort, C., Bodeau-Livinec, F., . . Cordier, S. (2015). Perinatal exposure to chlordecone and infant growth. Environ Res, 142, 123-134. doi:10.1016/j.envres.2015.06.023

Dallaire, R., Muckle, G., Rouget, F., Kadhel, P., Bataille, H., Guldner, L., . . Cordier, S. (2012). Cognitive, visual, and motor development of 7-month-old Guadeloupean infants exposed to chlordecone. Environ Res, 118, 79-85. doi:10.1016/j.envres.2012.07.006

Dennis, R. J., Beer, J. M., Baldwin, J. B., Ivan, D. J., Lorusso, F. J., \& Thompson, W. T. (2004). Using the Freiburg Acuity and Contrast Test to measure visual performance in USAF personnel after PRK. Optom Vis Sci, 81(7), 516-524. Retrieved from https://www.ncbi.nlm.nih.gov/pubmed/15252351 
Desaiah, D. (1985). Chlordecone interaction with catecholamine binding and uptake in rat brain synaptosomes. Neurotoxicology, 6(1), 159-165. Retrieved from https://www.ncbi.nlm.nih.gov/pubmed/2581192

Domenici, L., Trimarchi, C., Piccolino, M., Fiorentini, A., \& Maffei, L. (1985). Dopaminergic drugs improve human visual contrast sensitivity. Hum Neurobiol, 4(3), 195-197. Retrieved from https://www.ncbi.nlm.nih.gov/pubmed/4066428

Dubuisson, C., Heraud, F., Leblanc, J. C., Gallotti, S., Flamand, C., Blateau, A., ... Volatier, J. L. (2007). Impact of subsistence production on the management options to reduce the food exposure of the Martinican population to Chlordecone. Regul Toxicol Pharmacol, 49(1), 5-16. doi:10.1016/j.yrtph.2007.04.008

End, D. W., Carchman, R. A., \& Dewey, W. L. (1981). Neurochemical correlates of chlordecone neurotoxicity. J Toxicol Environ Health, 8(5-6), 707-718. doi:10.1080/15287398109530107

Eskenazi, B., Marks, A. R., Bradman, A., Fenster, L., Johnson, C., Barr, D. B., \& Jewell, N. P. (2006). In utero exposure to dichlorodiphenyltrichloroethane (DDT) and dichlorodiphenyldichloroethylene (DDE) and neurodevelopment among young Mexican American children. Pediatrics, 118(1), 233-241. doi:10.1542/peds.20053117

Fillion, M., Lemire, M., Philibert, A., Frenette, B., Weiler, H. A., Deguire, J. R., . . Mergler, D. (2013). Toxic risks and nutritional benefits of traditional diet on near visual contrast sensitivity and color vision in the Brazilian Amazon. Neurotoxicology, 37, 173-181. doi:10.1016/j.neuro.2013.04.010

Frenette, B., Mergler, D., \& Bowler, R. (1991). Contrast-sensitivity loss in a group of former microelectronics workers with normal visual acuity. Optom Vis Sci, 68(7), 556-560. Retrieved from https://www.ncbi.nlm.nih.gov/pubmed/1923329

Godard, E., \& Guldner, L. (2011). Évaluation et gestion du risque alimentaire associé au chlordécone pour les populations de Guadeloupe et de Martinique. BEH. Numéro thématique-Chlordécone aux Antilles : bilan actualisé des risques sanitaires, 3-45, 34-36.

Grandjean, P., \& Landrigan, P. J. (2006). Developmental neurotoxicity of industrial chemicals. Lancet, 368(9553), 2167-2178. doi:10.1016/S0140-6736(06)69665-7

Grandjean, P., White, R. F., Sullivan, K., Debes, F., Murata, K., Otto, D. A., \& Weihe, P. (2001). Impact of contrast sensitivity performance on visually presented 
neurobehavioral tests in mercury-exposed children. Neurotoxicol Teratol, 23(2), 141-146. Retrieved from http://www.ncbi.nlm.nih.gov/pubmed/11348831

Hammond, B., Katzenellenbogen, B. S., Krauthammer, N., \& McConnell, J. (1979).

Estrogenic activity of the insecticide chlordecone (Kepone) and interaction with uterine estrogen receptors. Proc Natl Acad Sci U S A, 76(12), 6641-6645. doi:10.1073/pnas.76.12.6641

Hong, J. S., Hudson, P. M., Yoshikawa, K., Ali, S. F., \& Mason, G. A. (1985). Effects of chlordecone administration on brain and pituitary peptide systems. Neurotoxicology, 6(1), 167-182. Retrieved from https://www.ncbi.nlm.nih.gov/pubmed/2581193

Horton, M. K., Kahn, L. G., Perera, F., Barr, D. B., \& Rauh, V. (2012). Does the home environment and the sex of the child modify the adverse effects of prenatal exposure to chlorpyrifos on child working memory? Neurotoxicol Teratol, 34(5), 534-541. doi:10.1016/j.ntt.2012.07.004

Hudson, P. M., Yoshikawa, K., Ali, S. F., Lamb, J. C. t., Reel, J. R., \& Hong, J. S. (1984). Estrogen-like activity of chlordecone (kepone) on the hypothalamopituitary axis: effects on the pituitary enkephalin system. Toxicol Appl Pharmacol, 74(3), 383-389. Retrieved from https://www.ncbi.nlm.nih.gov/pubmed/6204421

Jin, Y., Hein, M. J., Deddens, J. A., \& Hines, C. J. (2011). Analysis of lognormally distributed exposure data with repeated measures and values below the limit of detection using SAS. Ann Occup Hyg, 55(1), 97-112.

doi:10.1093/annhyg/meq061

Kavlock, R. J., Chernoff, N., Rogers, E., \& Whitehouse, D. (1980). Comparative tissue distribution of mirex and chlordecone in fetal and neonatal rats. Pesticide Biochemistry and Physiology, 14(3), 227-235. doi:https://doi.org/10.1016/00483575(80)90029-2

Komulainen, H., \& Bondy, S. C. (1987). Modulation of levels of free calcium within synaptosomes by organochlorine insecticides. J Pharmacol Exp Ther, 241(2), 575-581. Retrieved from https://www.ncbi.nlm.nih.gov/pubmed/2437290

Kuiper, G. G., Lemmen, J. G., Carlsson, B., Corton, J. C., Safe, S. H., van der Saag, P. T., ... Gustafsson, J. A. (1998). Interaction of estrogenic chemicals and phytoestrogens with estrogen receptor beta. Endocrinology, 139(10), 4252-4263. doi:10.1210/endo.139.10.6216 
Lai, Y. H., Wang, H. Z., \& Hsu, H. T. (2011). Development of visual acuity in preschool children as measured with Landolt $\mathrm{C}$ and Tumbling E charts. J AAPOS, 15(3), 251-255. doi:10.1016/j.jaapos.2011.03.010

Lebel, J., Mergler, D., Branches, F., Lucotte, M., Amorim, M., Larribe, F., \& Dolbec, J. (1998). Neurotoxic effects of low-level methylmercury contamination in the Amazonian Basin. Environ Res, 79(1), 20-32. doi:10.1006/enrs.1998.3846

Lee, Y. M., Kim, K. S., Kim, S. A., Hong, N. S., Lee, S. J., \& Lee, D. H. (2014). Prospective associations between persistent organic pollutants and metabolic syndrome: a nested case-control study. Sci Total Environ, 496, 219-225. doi:10.1016/j.scitotenv.2014.07.039

Lemaire, G., Mnif, W., Mauvais, P., Balaguer, P., \& Rahmani, R. (2006). Activation of alpha- and beta-estrogen receptors by persistent pesticides in reporter cell lines. Life Sci, 79(12), 1160-1169. doi:10.1016/j.lfs.2006.03.023

Loumann Knudsen, L. (2003). Visual acuity testing in diabetic subjects: the decimal progression chart versus the Freiburg visual acuity test. Graefes Arch Clin Exp Ophthalmol, 241(8), 615-618. doi:10.1007/s00417-003-0707-8

Mactutus, C. F., \& Tilson, H. A. (1985). Evaluation of long-term consequences in behavioral and/or neural function following neonatal chlordecone exposure. Teratology, 31(2), 177-186. doi:10.1002/tera.1420310202

Marks, A. R., Harley, K., Bradman, A., Kogut, K., Barr, D. B., Johnson, C., . . Eskenazi, B. (2010). Organophosphate pesticide exposure and attention in young MexicanAmerican children: the CHAMACOS study. Environ Health Perspect, 118(12), 1768-1774. doi:10.1289/ehp.1002056

McCarthy, M. M., Nugent, B. M., \& Lenz, K. M. (2017). Neuroimmunology and neuroepigenetics in the establishment of sex differences in the brain. Nat Rev Neurosci, 18(8), 471-484. doi:10.1038/nrn.2017.61

Molloy, C. S., Stokes, S., Makrides, M., Collins, C. T., Anderson, P. J., \& Doyle, L. W. (2016). Long-term effect of high-dose supplementation with DHA on visual function at school age in children born at $<33 \mathrm{wk}$ gestational age: results from a follow-up of a randomized controlled trial. Am J Clin Nutr, 103(1), 268-275. doi:10.3945/ajcn.115.114710 
Parkinson, D. (1989). Evidence for a dopaminergic innervation of cat primary visual cortex. Neuroscience, 30(1), 171-179. Retrieved from https://www.ncbi.nlm.nih.gov/pubmed/2526305

Philippat, C., Barkoski, J., Tancredi, D. J., Elms, B., Barr, D. B., Ozonoff, S., . . HertzPicciotto, I. (2018). Prenatal exposure to organophosphate pesticides and risk of autism spectrum disorders and other non-typical development at 3 years in a highrisk cohort. Int J Hyg Environ Health, 221(3), 548-555. doi:10.1016/j.ijheh.2018.02.004

Puertas, R., Lopez-Espinosa, M. J., Cruz, F., Ramos, R., Freire, C., Perez-Garcia, M., .. . Olea, N. (2010). Prenatal exposure to mirex impairs neurodevelopment at age of 4 years. Neurotoxicology, 31(1), 154-160. doi:10.1016/j.neuro.2009.09.009

Rauh, V. A., Garcia, W. E., Whyatt, R. M., Horton, M. K., Barr, D. B., \& Louis, E. D. (2015). Prenatal exposure to the organophosphate pesticide chlorpyrifos and childhood tremor. Neurotoxicology, 51, 80-86. doi:10.1016/j.neuro.2015.09.004

Raven, J., Raven, J. C., \& Court, J. H. (1998). Manual for Raven's Progressive Matrices and Vocabulary Scales. Oxford, England: Oxford Psychologists Press.

Ribas-Fito, N., Cardo, E., Sala, M., Eulalia de Muga, M., Mazon, C., Verdu, A., . . . Sunyer, J. (2003). Breastfeeding, exposure to organochlorine compounds, and neurodevelopment in infants. Pediatrics, 111(5 Pt 1), e580-585. Retrieved from https://www.ncbi.nlm.nih.gov/pubmed/12728113

Ribas-Fito, N., Torrent, M., Carrizo, D., Munoz-Ortiz, L., Julvez, J., Grimalt, J. O., \& Sunyer, J. (2006). In utero exposure to background concentrations of DDT and cognitive functioning among preschoolers. Am J Epidemiol, 164(10), 955-962. doi:10.1093/aje/kwj299

Riva, E., Grandi, F., Massetto, N., Radaelli, G., Giovannini, M., Zetterstrom, R., \& Agostoni, C. (2004). Polychlorinated biphenyls in colostral milk and visual function at 12 months of life. Acta Paediatr, 93(8), 1103-1107. Retrieved from https://www.ncbi.nlm.nih.gov/pubmed/15456203

Sagiv, S. K., Thurston, S. W., Bellinger, D. C., Tolbert, P. E., Altshul, L. M., \& Korrick, S. A. (2010). Prenatal organochlorine exposure and behaviors associated with attention deficit hyperactivity disorder in school-aged children. Am J Epidemiol, 171(5), 593-601. doi:10.1093/aje/kwp427 
Schuh, R. A., Richardson, J. R., Gupta, R. K., Flaws, J. A., \& Fiskum, G. (2009). Effects of the organochlorine pesticide methoxychlor on dopamine metabolites and transporters in the mouse brain. Neurotoxicology, 30(2), 274-280. Retrieved from https://www.ncbi.nlm.nih.gov/pubmed/19459224

Schulze-Bonsel, K., Feltgen, N., Burau, H., Hansen, L., \& Bach, M. (2006). Visual acuities "hand motion" and "counting fingers" can be quantified with the freiburg visual acuity test. Invest Ophthalmol Vis Sci, 47(3), 1236-1240.

doi:10.1167/iovs.05-0981

Sharma, H., Zhang, P., Barber, D. S., \& Liu, B. (2010). Organochlorine pesticides dieldrin and lindane induce cooperative toxicity in dopaminergic neurons: role of oxidative stress. Neurotoxicology, 31(2), 215-222.

doi:10.1016/j.neuro.2009.12.007

Suarez-Lopez, J. R., Himes, J. H., Jacobs, D. R., Jr., Alexander, B. H., \& Gunnar, M. R. (2013). Acetylcholinesterase activity and neurodevelopment in boys and girls. Pediatrics, 132(6), e1649-1658. doi:10.1542/peds.2013-0108

Taylor, J. R. (1982). Neurological manifestations in humans exposed to chlordecone and follow-up results. Neurotoxicology, 3(2), 9-16. Retrieved from https://www.ncbi.nlm.nih.gov/pubmed/6186968

Taylor, J. R., Selhorst, J. B., Houff, S. A., \& Martinez, A. J. (1978). Chlordecone intoxication in man. I. Clinical observations. Neurology, 28(7), 626-630. Retrieved from https://www.ncbi.nlm.nih.gov/pubmed/79155

Till, C., Westall, C. A., Koren, G., Nulman, I., \& Rovet, J. F. (2005). Vision abnormalities in young children exposed prenatally to organic solvents. Neurotoxicology, 26(4), 599-613. doi:10.1016/j.neuro.2005.05.011

Torres-Sanchez, L., Rothenberg, S. J., Schnaas, L., Cebrian, M. E., Osorio, E., Del Carmen Hernandez, M., . . . Lopez-Carrillo, L. (2007). In utero p,p'-DDE exposure and infant neurodevelopment: a perinatal cohort in Mexico. Environ Health Perspect, 115(3), 435-439. doi:10.1289/ehp.9566

Van den Boomen, C., de Graaff, J. C., de Jong, T. P., Kalkman, C. J., \& Kemner, C. (2013). General anesthesia as a possible GABAergic modulator affects visual processing in children. Front Cell Neurosci, 7, 42. doi:10.3389/fncel.2013.00042

van Wendel de Joode, B., Mora, A. M., Lindh, C. H., Hernandez-Bonilla, D., Cordoba, L., Wesseling, C., . . . Mergler, D. (2016). Pesticide exposure and 
neurodevelopment in children aged 6-9 years from Talamanca, Costa Rica. Cortex, 85, 137-150. doi:10.1016/j.cortex.2016.09.003

Vested, A., Ramlau-Hansen, C. H., Olsen, S. F., Bonde, J. P., Stovring, H., Kristensen, S. L., . . Toft, G. (2014). In utero exposure to persistent organochlorine pollutants and reproductive health in the human male. Reproduction, 148(6), 635-646. doi:10.1530/REP-13-0488

Vrijheid, M., Casas, M., Gascon, M., Valvi, D., \& Nieuwenhuijsen, M. (2016). Environmental pollutants and child health-A review of recent concerns. Int J Hyg Environ Health, 219(4-5), 331-342. doi:10.1016/j.ijheh.2016.05.001

Wagner-Schuman, M., Richardson, J. R., Auinger, P., Braun, J. M., Lanphear, B. P., Epstein, J. N., . . Froehlich, T. E. (2015). Association of pyrethroid pesticide exposure with attention-deficit/hyperactivity disorder in a nationally representative sample of U.S. children. Environ Health, 14, 44. doi:10.1186/s12940-015-0030-y

Waksman, J. C., \& Brody, A. (2007). Contrast sensitivity in occupational and environmental neurotoxicology: what does it really mean? Arch Environ Occup Health, 62(4), 177-181. doi:10.3200/AEOH.62.4.177-181

Witkovsky, P., \& Schutte, M. (1991). The organization of dopaminergic neurons in vertebrate retinas. Vis Neurosci, 7(1-2), 113-124. Retrieved from https://www.ncbi.nlm.nih.gov/pubmed/1931794 
Table 1. Descriptive characteristics of the participants $(n=285)$.

\begin{tabular}{|c|c|c|c|c|c|c|}
\hline & $\mathrm{N}$ & $\%$ & Median & Mean & SD & Range (min-max) \\
\hline \multicolumn{7}{|l|}{ Child characteristics } \\
\hline Age at the testing time (years) & 285 & & 7.70 & 7.68 & 0.2127 & $0.90(7.10-8.00)$ \\
\hline Gestational age (weeks) & 285 & & 39.00 & 38.46 & 1.573 & $7.00(34.00-41.00)$ \\
\hline Sex (\% male) & 285 & 45.6 & & & & \\
\hline Breastfeeding (\% yes) & 243 & 85.3 & & & & \\
\hline$<3$ months & 40 & 14.0 & & & & \\
\hline 3-7 months & 83 & 29.1 & & & & \\
\hline$>7-18$ months & 66 & 23.2 & & & & \\
\hline$>18$ months & 54 & 18.9 & & & & \\
\hline Wearing glasses (\% yes)a & 281 & 29.8 & & & & \\
\hline \multicolumn{7}{|l|}{ Maternal characteristics } \\
\hline Age at birth time (years) & 285 & & 32.63 & 31.72 & 6.76 & $20.03(15.10-45.14)$ \\
\hline Education & 293 & & & & & \\
\hline$\leq$ 12th Grade (Bac) & 144 & 50.5 & & & & \\
\hline$>$ 12th Grade & 141 & 49.5 & & & & \\
\hline Smoking at inclusion (\% yes) & 285 & 2.8 & & & & \\
\hline Alcohol at inclusion (\% yes) & 278 & 2.5 & & & & \\
\hline Raven's Progressive Matrices score & 268 & & 37.00 & 35.46 & 12.23 & $49(9-58)$ \\
\hline \multicolumn{7}{|l|}{ Chlordecone exposures } \\
\hline \multicolumn{7}{|l|}{ Cord } \\
\hline$\%<$ LOD & 62 & 21.8 & & & & \\
\hline
\end{tabular}




\begin{tabular}{lllllll}
$\quad$ Concentration $(\mu \mathrm{g} / \mathrm{L})$ & 223 & & 0.30 & 0.80 & 2.77 & $29.72(0.06-29.78)$ \\
$\begin{array}{l}\text { Child } \\
\quad \%<\text { LOD }\end{array}$ & 73 & 26.7 & & & & \\
$\quad \begin{array}{l}\text { Concentration }(\mu \mathrm{g} / \mathrm{L}) \\
\text { Freiburg Acuity and Contrast Test }\end{array}$ & 209 & & 0.08 & 0.17 & 0.52 & $6.99(0.02-7.01)$ \\
$\begin{array}{l}\text { Acuity (Snellen fraction ratio) } \\
\text { Contrast sensitivity (\%) }\end{array}$ & 263 & 92.20 & 1.33 & 1.36 & 0.41 & $1.72(0.28-2.00)$ \\
\hline
\end{tabular}

${ }^{\text {a }}$ At the testing time

SD : Standard deviation 
Table 2. Associations between chlordecone exposure and visual contrast sensitivity.

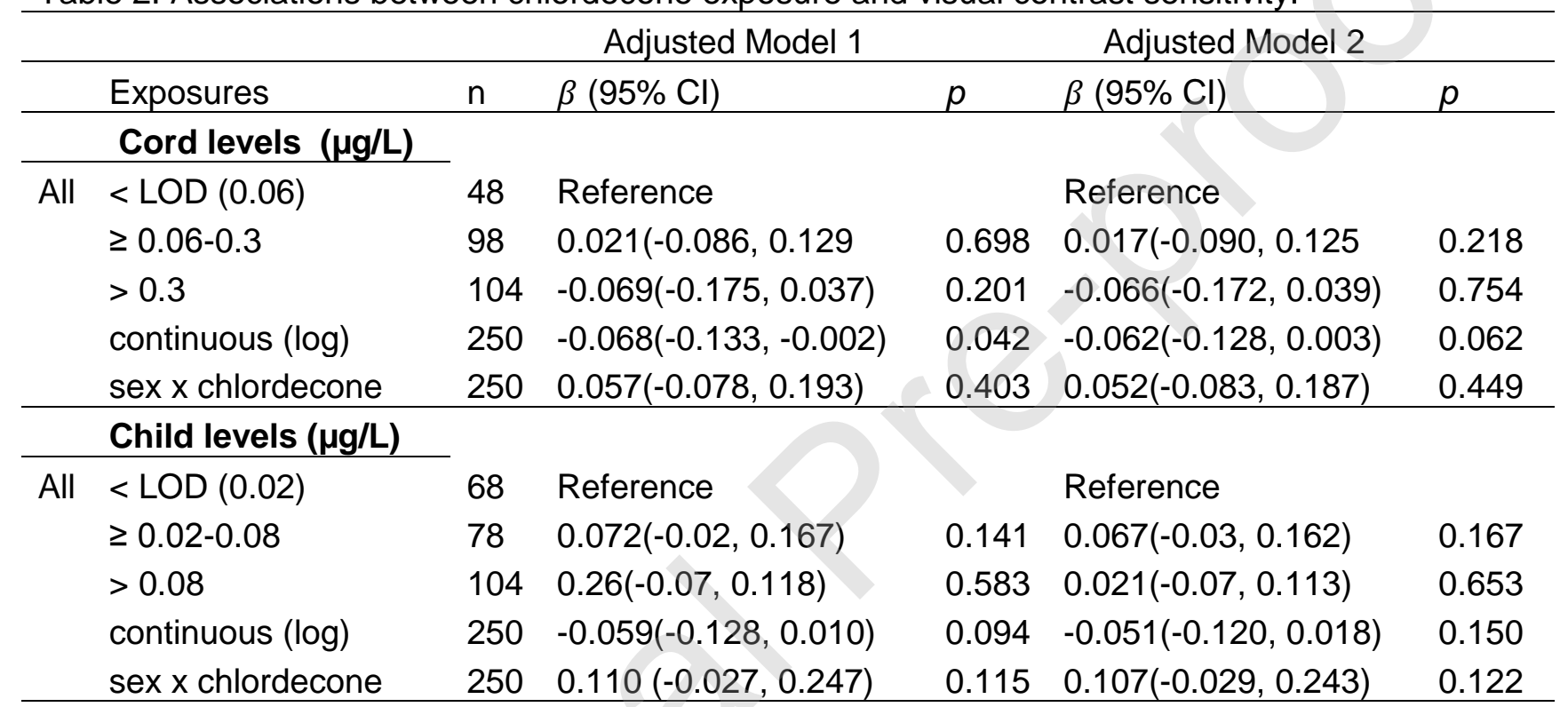

Model 1: adjusted for child sex and age, maternal IQ (Raven score), maternal education, maternal alcohol intake during pregrancy and plasma lipids.

Model 2: additional adjustment for the complementary chlordecone exposure (i.e., child levels when the cord levels was the variable of interest, and vice versa). 